\title{
Metastatic colorectal cancer first-line treatment with bevacizumab: the impact of K-ras mutation
}

This article was published in the following Dove Press journal:

OncoTargets and Therapy

28 November 2013

Number of times this article has been viewed

\section{Luigi Rossi ${ }^{1,2}$ \\ Enzo Veltri ${ }^{3}$ \\ Angelo Zullo ${ }^{4}$ \\ Federica Zoratto' \\ Maria Colonna ${ }^{5}$ \\ Flavia Longo ${ }^{6}$ \\ Marcella Mottolese ${ }^{7}$ \\ Diana Giannarelli ${ }^{8}$ \\ Luigi Ruco' \\ Paolo Marchetti ${ }^{10}$ \\ Adriana Romiti ${ }^{10}$ \\ Viola Barucca ${ }^{10}$ \\ Giuseppe Giannini'" \\ Loredana Bianchi' \\ Silverio Tomao'}

'Department of Medico-Surgical Sciences and Biotechnologies, Sapienza University of Rome, Rome, Italy; ${ }^{2}$ Oncology Unit, ICOT Hospital, Latina, Italy; ${ }^{3}$ Oncology Unit, SM Goretti Hospital, Latina, Italy; ${ }^{4}$ Gastroenterology and Digestive Endoscopy Unit, Nuovo Regina Margherita Hospital, Rome, Italy; ${ }^{5}$ Oncology Unit, Don Luigi di Liegro Hospital, Gaeta, Italy; ' Oncology Unit, Umberto I Policlinico di Roma Hospital, Sapienza University of Rome, Rome, Italy; ${ }^{7}$ Department of Pathology, ${ }^{8}$ Biostatistics and Scientific Direction, Regina Elena National Cancer Institute, Rome, Italy; ' ${ }^{9}$ Department of Pathology, ${ }^{10}$ Oncology Unit, Sant'Andrea Hospital, "Department of Pathology, Umberto I Policlinico di Roma Hospital, Sapienza University of Rome, Rome, Italy

Correspondence: Luigi Rossi Oncology Unit, ICOT Hospital, 1668 Franco Faggiana Street, Latina 04100, Italy

Tel +3934956434l8

$\mathrm{Fax}+39077365 \mathrm{I} 3342$

Email dr.rossi@ymail.com
Background: Bevacizumab plus chemotherapy prolongs progression-free survival (PFS) and overall survival (OS) in metastatic colorectal cancer (mCRC). Although there is strong evidence to suggest that the mutational status of the K-ras oncogene has a role as a predictive factor for activity in patients treated with cetuximab and panitumumab, few data have been obtained in patients treated with bevacizumab. We conducted an additional retrospective analysis to investigate the prognostic value of K-ras mutation relative to mCRC first-line treatment with bevacizumab.

Materials and methods: A total of 108 patients were retrospectively reviewed. K-ras status was assessed in the overall population by sequencing. Statistical association for PFS and OS was analyzed using the Kaplan-Meier method, and the prognostic role of K-ras was determined using the logrank test.

Results: Median PFS was 10 months both for patients with wild-type (WT) K-ras and mutated (MT) K-ras (hazard ratio [HR] 0.94, $P=0.75$ ); neither difference in median OS was significant (27 months WT K-ras versus 26 months MT K-ras, HR 0.92; $P=0.70$ ). A further analysis was carried out in the two groups according to metastatic sites. No statistically significant difference in terms of PFS and OS was demonstrated between WT K-ras and MT K-ras with liver metastases only and in those with extrahepatic disease.

Conclusion: Although further study is required, our results seem to confirm that K-ras mutation does not have a prognostic role in mCRC patients receiving first-line treatment with bevacizumab

Keywords: K-ras, bevacizumab, prognostic factor, metastatic colorectal cancer, liver metastases, extrahepatic disease

\section{Introduction}

Predictive and prognostic tumor markers are playing an increasingly important role in personalized metastatic colorectal cancer (mCRC) care. ${ }^{1,2}$ These tags range from conventional single protein-, ribonucleic acid- or deoxyribonucleic acid (DNA)-based markers to molecular signatures based on multiplex assays, and they are used to guide clinical management of patients. ${ }^{3}$ Currently, biomolecular factors with ascertained predictive and prognostic value in $\mathrm{mCRC}$ are the $\mathrm{K}$-ras and $B R A F$ oncogenes, respectively. ${ }^{4-10}$ K-ras, the human homologue of the Kirsten rat sarcoma 2 virus oncogene, encodes a small guanosine triphosphate-binding protein that acts as a self-inactivating signal transducer by cycling from guanosine diphosphate- to guanosine triphosphatebound states in response to stimulation of a cell-surface receptor. ${ }^{11,12} \mathrm{~K}$-ras can harbor oncogenic mutation that yields a constitutively active protein. Mutations (mainly at 
exons 2 and 3 ) occur early in the progression of colorectal adenoma to carcinoma and they are found in approximately $30 \%-50 \%$ of CRC. ${ }^{5,11,13,14}$ The identification of a biologic and a clinical role for K-ras mutation marked a turning point in the scenario of mCRC treatment. As a matter of a fact, the importance of K-ras and its downstream signaling pathways in tumor development is well established. In the last few years, K-ras mutation has acquired an essential clinical significance as a negative predictive factor in $\mathrm{mCRC}$ patients treated with anti-epidermal growth factor receptor (EGFR) agents, such as cetuximab and panitumumab. ${ }^{1,2}$ In addition, the prognostic value of tumor K-ras status has been extensively evaluated, but results have been conflicting. Some studies have demonstrated a prognostic effect, ${ }^{1,5}$ while others have failed. ${ }^{6}$

The interaction of EGFR and vascular endothelial growth factor (VEGF) is well known. ${ }^{15,16}$ Bevacizumab, a humanized monoclonal antibody that binds to and neutralizes VEGF-A, has been widely used in various $\mathrm{mCRC}$ treatment lines, improving response rates, progression-free survival (PFS), and overall survival (OS). ${ }^{17-24}$ At the time, anti-VEGF predictive and prognostic factors were not found, and the role of K-ras-mutation status in patients undergoing treatment with bevacizumab remains of great interest. Furthermore, it has been ascertained that K-ras mutation is also associated with specific clinical signatures of tumor as an increased risk of metastasis in lung and brain, even if does not modify the risk of metastasis in the liver. ${ }^{25}$

In a previous study, we examined the role of K-ras status as a predictive factor of response on antiangiogenic therapy, affirming that bevacizumab provides clinical benefit and objective response rate in $\mathrm{mCRC}$ patients independently of K-ras expression and metastatic sites. ${ }^{26}$

Moving from such an appealing biological and clinical background, we planned an additional retrospective analysis aimed at the identification of a possible prognostic role of $\mathrm{K}$-ras in $\mathrm{mCRC}$ patients treated with first-line chemotherapy plus bevacizumab. Correlations between K-ras status and PFS and OS were analyzed. Furthermore, we evaluated whether K-ras mutation could influence the outcome of patients with liver metastases only, in comparison to patients with extrahepatic disease.

\section{Materials and methods}

\section{Patients and study design}

The design of this study has been reported previously. ${ }^{26}$ In brief, this was a retrospective study enrolling consecutive 108 unresectable mCRC patients, treated in clinical practice in three Italian oncology centers (Rome, Latina, Gaeta) between September 2008 and March 2011. Patients with histologically confirmed mCRC, Eastern Cooperative Oncology Group performance status $\leq 2$, assessment of K-ras mutation status, no previous chemotherapy for advanced disease, treated with first-line chemotherapy with either the FOLFOX (oxaliplatin, leucovorin, and fluorouracil) or FOLFIRI (folic acid, fluorouracil, and irinotecan) regimen combined with bevacizumab, not a candidate for liver metastasis resection after chemotherapy, with adequate hepatic and renal function, and no contraindications to bevacizumab therapy were included.

The primary end point of this study was to assess the prognostic value of tumor K-ras status on PFS and OS of mCRC patients treated with first-line chemotherapy plus bevacizumab; secondary end points included evaluation of how K-ras mutation could influence the outcome of patients with liver metastases only with respect to patients with extrahepatic disease, clinical response PFS and OS of bevacizumab combined with chemotherapy in the overall population, and whether these same parameters differ between patients with hepatic metastases only and those with extrahepatic metastatic sites. Response rates to treatment with bevacizumab according to K-ras expression have been reported in our previous retrospective study. ${ }^{26}$ Survival results were last updated in March 2012. PFS was defined as the time from the beginning of the treatment until the first observation of disease progression or death from any cause, while OS was defined as the time from the beginning of the treatment until death from any cause. Finally, patients with extrahepatic metastatic disease were defined as patients with metastases both in the liver and in other organs or with metastases not present in the liver but in other sites.

\section{K-ras-mutation analysis}

Evaluation of K-ras status was performed retrospectively on primary tumor samples only. K-ras analysis was performed centrally using existing platforms. DNA was extracted from paraffin-embedded CRC samples after histological control for at least $50 \%$ of tumor cells. Mutations at codons 12, 13, and 61 were assessed by means of direct sequencing with a polymerase chain reaction (PCR) method. ${ }^{27}$

\section{Statistical analysis}

PFS and OS curves were calculated according to K-ras tumormutation status using the Kaplan-Meier method. The prognostic value of the biological marker was determined using the logrank test. A $P$-value of less than 0.05 was considered significant. 


\section{Results}

A total of $108 \mathrm{mCRC}$ patients were consecutively enrolled in three Italian oncology units between September 2008 and March 2011. Tumor K-ras status was assessed in the entire population. In total, 69 (64\%) patients had wild-type (WT) K-ras tumors, while 39 (36\%) patients had mutated (MT) K-ras. The main patient characteristics according to K-ras status are shown in Table 1. Significant differences were observed between the two groups in primary side of origin, metastatic sites, primitive tumor resection, prior adjuvant chemotherapy, and chemotherapy first-line regimen. Regarding metastatic sites, liver metastases only were present in 53 patients (41 WT K-ras patients versus twelve MT K-ras patients), extrahepatic disease affected 55 patients (28 WT K-ras patients versus $27 \mathrm{MT}$ K-ras patients); among the extrahepatic sites were reported 56\% lung, 31\% peritoneal, $2 \%$ brain, and $11 \%$ other sites. In particular, $61.3 \%$ and $2 \%$ of patients with lung and brain metastases, respectively, had MT K-ras tumors.

PFS and OS were obtained from 106 of 108 patients, as two patients were lost to follow-up. In the overall population, median PFS (mPFS) and median OS (mOS) were 10 months (95\% confidence interval [CI] 8.9-11.1) and 26 months (95\% CI 23.5-28.5), respectively, with 86 (81\%) deaths at last survival update.

mPFS was the same between WT K-ras and MT K-ras (10 months, hazard ratio [HR] 0.94, 95\% CI

Table I Baseline characteristics of patients included in the K-ras analysis according to tumor K-ras status

\begin{tabular}{|c|c|c|c|}
\hline Characteristic & $\begin{array}{l}\text { WT K-ras } \\
(n=69)\end{array}$ & $\begin{array}{l}\text { MT K-ras } \\
(n=39)\end{array}$ & $P$-value \\
\hline Median age & 64 & 55 & NA \\
\hline years (range) & $(4 I-78)$ & $(39-79)$ & \\
\hline \multicolumn{4}{|l|}{ Sex } \\
\hline Male & 44 & 24 & 0.8 \\
\hline Female & 25 & 15 & \\
\hline ECOG PS & 0 & 0 & NA \\
\hline \multicolumn{4}{|l|}{ Primary tumor } \\
\hline Colon & 55 & 29 & 0.5 \\
\hline Rectum & 14 & 10 & \\
\hline \multicolumn{4}{|l|}{ Metastatic sites } \\
\hline Liver only & $4 I$ & 12 & 0.004 \\
\hline Extrahepatic & 28 & 27 & \\
\hline Primitive resection & 59 & 30 & 0.3 \\
\hline Adjuvant treatment & 14 & 6 & 0.3 \\
\hline \multicolumn{4}{|l|}{ First-line chemotherapy } \\
\hline FOLFIRI & 58 & 30 & 0.4 \\
\hline FOLFOX & II & 9 & \\
\hline
\end{tabular}

Abbreviations: ECOG PS, Eastern Cooperative Group performance status; WT, wild type; MT, mutant; NA, not available; FOLFIRI, folic acid, fluorouracil, and irinotecan; FOLFOX, oxaliplatin, leucovorin, and fluorouracil.
$0.62-1.40, P=0.75$ ) (Figure $1 \mathrm{~A})$. No statistically significant difference was observed in mOS either: patients with WT K-ras tumors had an mOS of 27 months versus 26 months for patients with MT K-ras tumors (HR 0.92, 95\% CI 0.58-1.42; $P=0.70$ ), with 55 versus 31 death events in the two groups, respectively (Figure 1B).

When patients were analyzed for metastatic sites, mPFS was 10.5 months in patients with liver metastases only versus 10 months in the extrahepatic disease group (HR 0.90, 95\% CI 0.59-1.32; $P=0.59$ ) (Figure 2A); similarly, identical mOS was observed in both groups (26 months, HR 1.28, 95\% CI 0.86-1.98; $P=0.72$ ) (Figure 2B).

Analyzing these two subpopulations according to K-ras expression, we obtained the following results: in patients with liver metastases only, mPFS was 11 months in the WT K-ras group versus 10 months in the MT K-ras group (HR 0.88, 95\% CI 0.41-1.77; $P=0.70$ ) (Figure 3A); mOS was greater in WT K-ras patients than in MT K-ras patients, but it was not statistically significant (27 months versus 21 months, respectively, HR 1.11, 95\% CI $0.50-2.45 ; P=0.78$ ) (Figure 3B). When metastatic disease was also extrahepatic or extrahepatic only, mPFS was 8.5 months in the WT K-ras group versus 10.5 months in the MT K-ras group (HR 1.04, 95\% CI 0.61-1.80; $P=0.87$ ) (Figure 4A), while mOS was 25.5 versus 26.5 months, respectively (HR 0.75 , 95\% CI $0.39-1.27 ; P=0.29$ ) (Figure 4B).

The administration of subsequent therapy lines after the discontinuation of first-line chemotherapy was examined. Patients treated with first-line FOLFIRI received second-line FOLFOX chemotherapy, and vice versa. All patients with WT K-ras tumors received either chemotherapy plus cetuximab in second-line therapy or one of the two anti-EGFR agents in third-line treatment (cetuximab in combination with irinotecan or monotherapy with panitumumab). However anti-EGFR agents did not induce OS difference between WT K-ras and MT K-ras tumors.

\section{Discussion}

In the overall population, the PFS and OS data regarding first-line mCRC treatment with chemotherapy and bevacizumab were modeled on literature data. ${ }^{18,21}$ Bevacizumab effectiveness was confirmed both in liver metastasis-only patients and in extrahepatic metastatic patients. The outcome of patients was not affected by subsequent anti-EGFR firstline chemotherapy; at the same time, several studies reported no difference between first-line chemotherapy based on the 


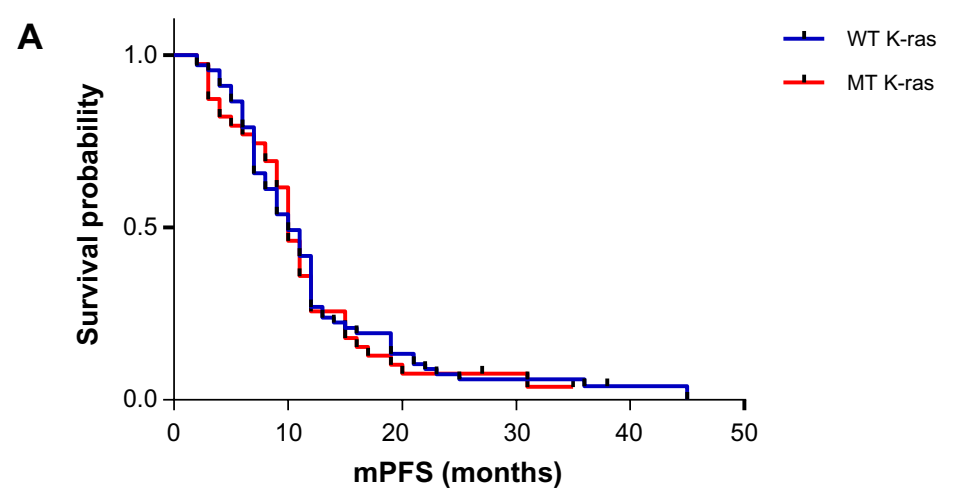

\begin{tabular}{lcccc}
\hline & Patients & Events & Censored & mPFS, months \\
\hline WT K-ras & 69 & 65 & 2 & 10 \\
MT K-ras & 39 & 37 & 2 & 10 \\
Log rank & $P=0.75$ & & & \\
HR & $0.94(95 \% \mathrm{Cl} 0.62-1.40)$ & & \\
\hline
\end{tabular}

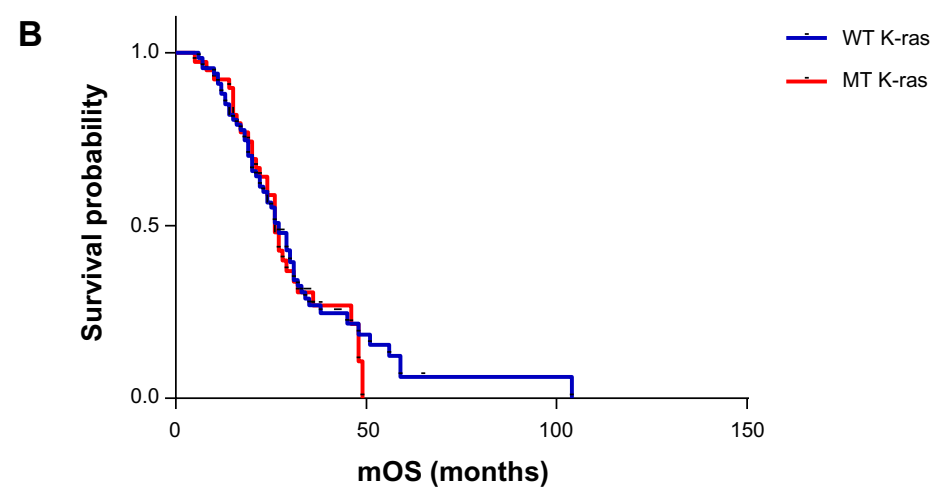

\begin{tabular}{lcccc}
\hline & Patients & Events & Censored & mos, months \\
\hline WT K-ras & 69 & 55 & 12 & 27 \\
MT K-ras & 39 & 31 & 8 & 26 \\
Log rank & $P=0.70$ & & & \\
HR & $0.92(95 \% \mathrm{Cl} 0.58-1.42)$ & & \\
\hline
\end{tabular}

Figure I (A) Progression-free survival according to K-ras status; (B) overall survival according to K-ras status.

Abbreviations: WT, wild type; MT, mutated; mPFS, median progression-free survival; mOS, median overall survival; $\mathrm{HR}$, hazard ratio; $\mathrm{Cl}$, confidence interval.

FOLFIRI regimen followed by second-line FOLFOX therapy, and vice versa. ${ }^{28-30}$

In this study, we addressed an important question, ie, whether K-ras status is a prognostic factor in mCRC patients receiving first-line chemotherapy plus bevacizumab, given the intimate relationship between the EGFR and VEGF signaling pathways. Our retrospective experience indicates that tumor K-ras status does not influence outcomes of patients treated with antiangiogenic therapy: patients with WT K-ras tumors had identical clinical benefit as those with MT K-ras tumors in terms of PFS (10 months) and near-identical clinical benefit in terms of OS (27 versus 26 months, respectively). A trend was observed in WT K-ras patients with liver metastases only compared with MT K-ras patients (PFS 11 versus 10 months and OS 27 versus 21 months, respectively), but this advantage was not statistically significant. 


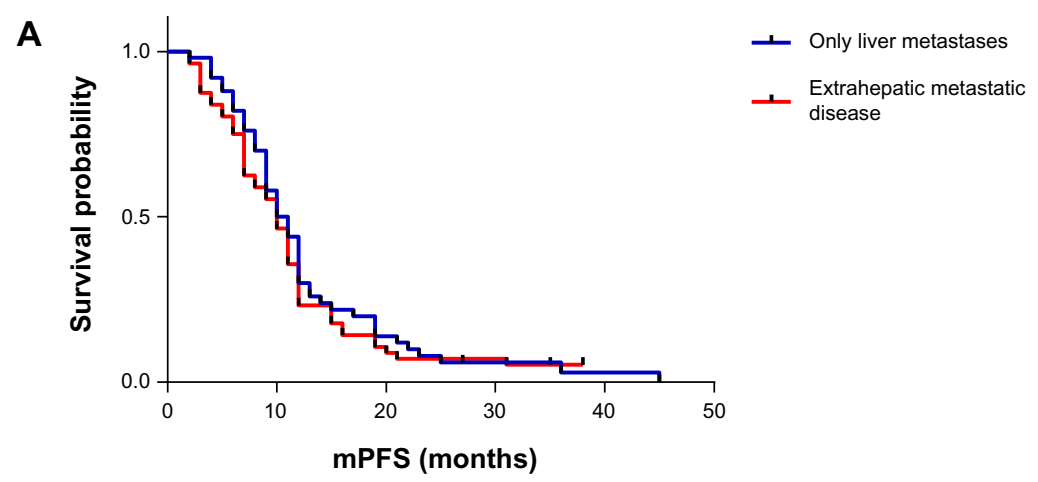

\begin{tabular}{lcccc}
\hline & Patients & Events & Censored & mPFS, months \\
\hline $\begin{array}{l}\text { Liver } \\
\text { metastases only }\end{array}$ & 53 & 49 & 4 & 10.5 \\
$\begin{array}{l}\text { Extrahepatic } \\
\text { metastatic sites }\end{array}$ & 55 & 53 & 2 & 10 \\
Log rank & $P=0.90$ & & & \\
HR & $0.94(95 \% \mathrm{Cl}$ 0.59-1.32) & & \\
\hline
\end{tabular}

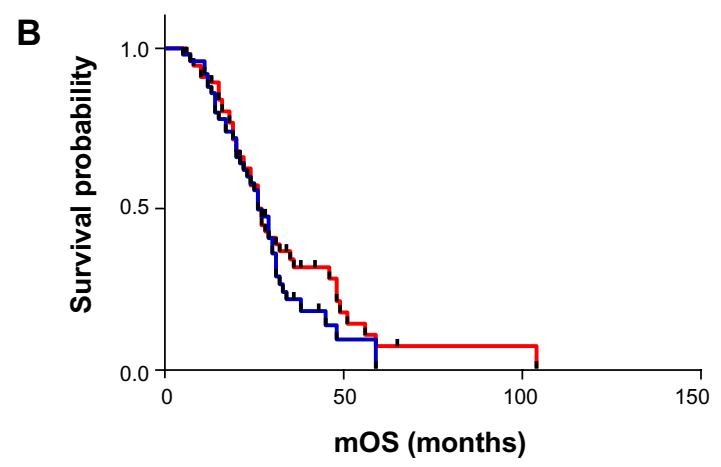
- Only liver metastases
ـ Extrahepatic metastatic disease

\begin{tabular}{lcccc}
\hline & Patients & Events & Censored & mos, months \\
\hline $\begin{array}{l}\text { Liver } \\
\text { metastases only }\end{array}$ & 53 & 41 & 12 & 26 \\
$\begin{array}{l}\text { Extrahepatic } \\
\text { metastatic sites }\end{array}$ & 55 & 45 & 10 & 26 \\
Log rank & $P=0.72$ & & \\
HR & $1.28(95 \% \mathrm{Cl} 0.86-1.98)$ & & \\
\hline
\end{tabular}

Figure 2 (A) Progression-free survival according to metastatic site; (B) overall survival according to metastatic site.

Abbreviations: mPFS, median progression-free survival; $\mathrm{mOS}$, median overall survival; $\mathrm{HR}$, hazard ratio; $\mathrm{Cl}$, confidence interval.

On the other hand, patients with MT K-ras tumors and extrahepatic disease appear to have a better prognosis than the WT K-ras group. Moreover, K-ras mutation is more frequently associated with extrahepatic disease, such as in the lung and brain, according to literature data. ${ }^{25}$ Some studies have suggested that MT K-ras is associated with aggressive
mCRC due to the presence of extrahepatic metastases, ${ }^{31,32}$ though in our analysis K-ras mutation was not correlated with poor prognoses.

Several studies have evaluated the role of K-ras status in $\mathrm{mCRC}$ patients receiving first-line treatment with bevacizumab (Table 2). Ince et al did not establish a statistically significant 


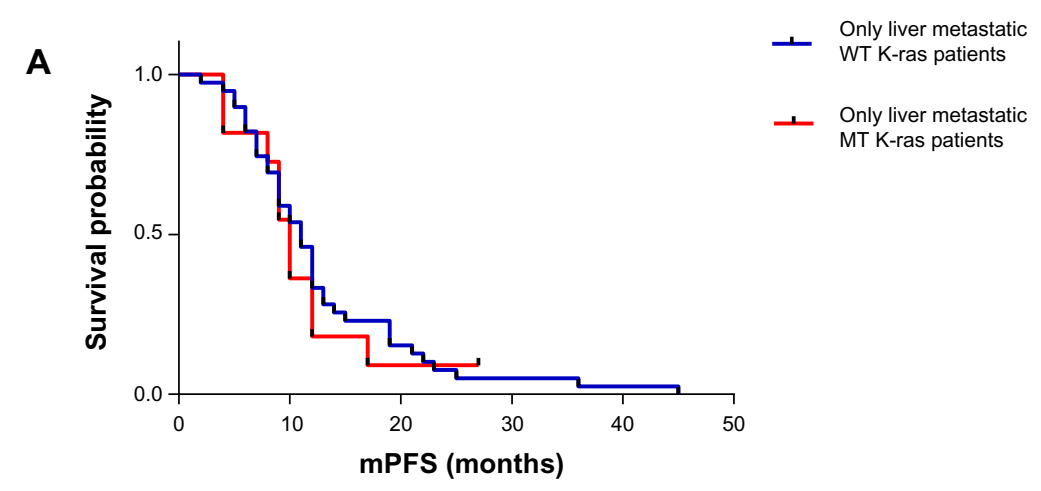

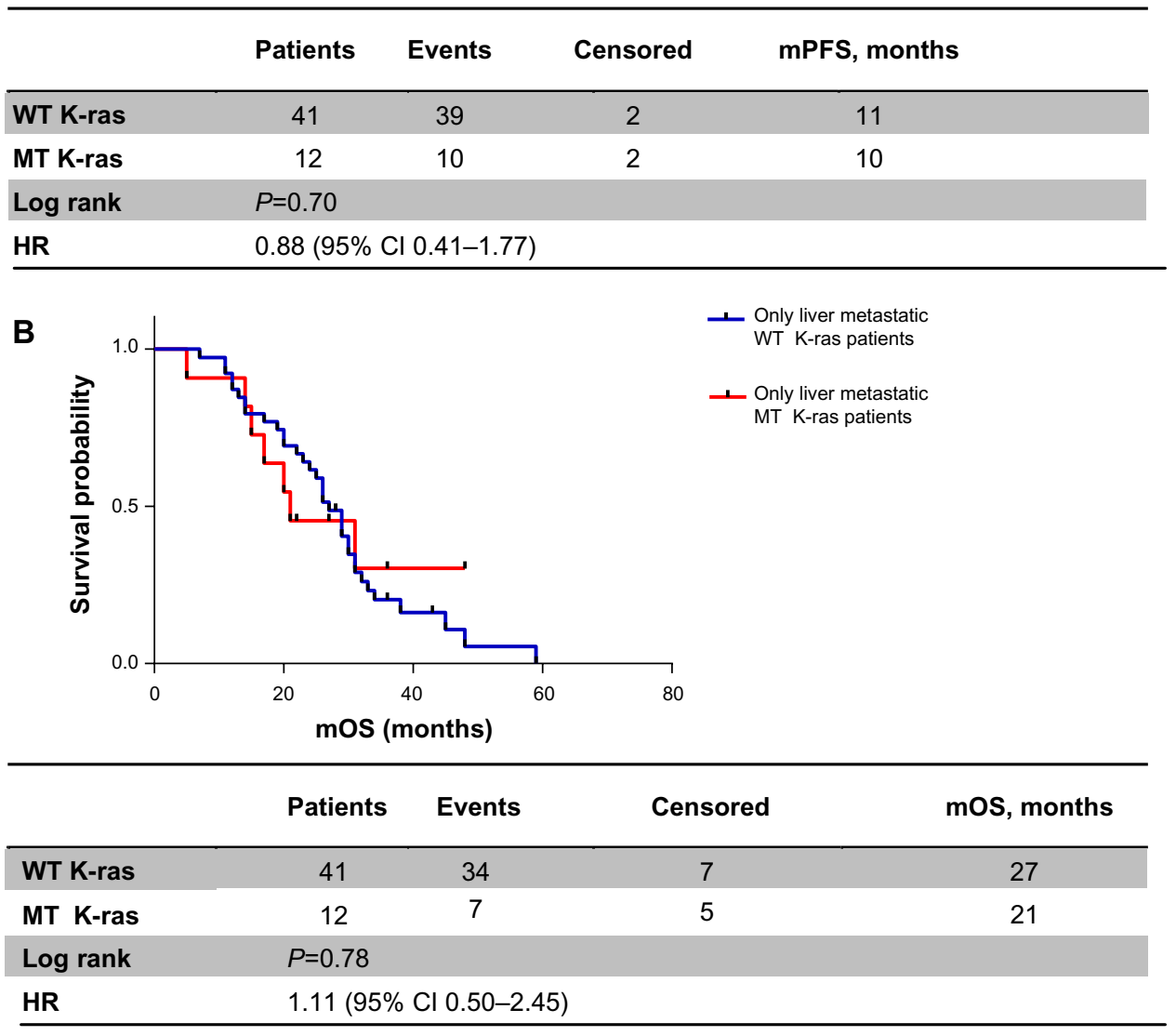

Figure 3 (A) Progression-free survival according to K-ras status in liver-only metastasis patients; (B) overall survival according to K-ras status in liver-only metastasis patients. Abbreviations: WT, wild type; MT, mutated; mPFS, median progression-free survival; $\mathrm{mOS}$, median overall survival; $\mathrm{HR}$, hazard ratio; $\mathrm{Cl}$, confidence interval.

difference in terms of OS between WT K-ras and MT K-ras in bevacizumab-treated patients. ${ }^{33}$ In a subsequent analysis by Hurwitz et al, PFS was greater for bevacizumab-treated patients with WT versus MT K-ras tumors. ${ }^{34}$ Recently, DíazRubio et al suggested a prognostic role for K-ras status in mCRC patients who were enrolled in the MACRO (maintenance treatment in advanced colorectal cancer) trial. ${ }^{35} \mathrm{~A}$ statistically significant difference was observed in OS and PFS between WT K-ras tumors and MT K-ras tumors, with a greater benefit of bevacizumab treatment in WT K-ras patients. On the contrary, other studies have reported that K-ras mutation is not a prognostic factor for patient outcome. ${ }^{24,36-39}$ Masi et al claimed that patients with K-ras mutations derive similar clinical benefit from bevacizumab compared with patients who have WT K-ras. ${ }^{36}$ This variability in results could be a result of several factors, including the number of patients included in different trials, the proportions of patients tested for K-ras mutation status and technology used, the chemotherapy regime under investigation, and subsequent second- and third-line therapies. ${ }^{39}$

Our analysis seems to be in agreement with studies that did not suggest any therapeutic implication of K-ras mutation when bevacizumab was given in addition to chemotherapy, ${ }^{24,36-39}$ but our study has several limitations. Firstly, 

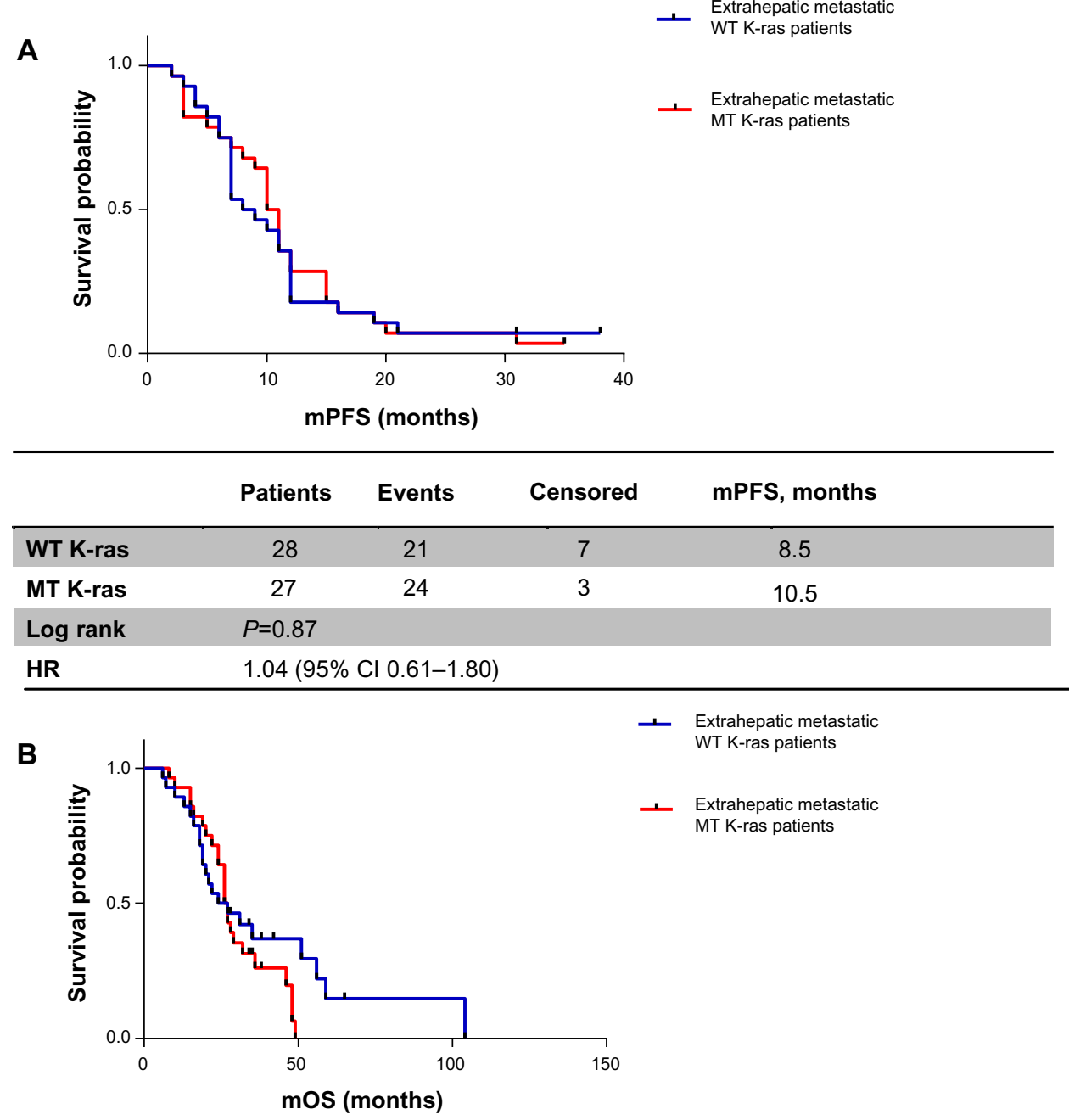

\begin{tabular}{lcccc}
\hline & Patients & Events & Censored & mOS, months \\
\hline WT K-ras & 28 & 26 & 2 & 25.5 \\
MT K-ras & 27 & 24 & 0 & 26.5 \\
Log rank & $P=0.29$ & & & \\
HR & $0.75(95 \% \mathrm{Cl} 0.39-1.27)$ & & \\
\hline
\end{tabular}

Figure 4 (A) Progression-free survival according to K-ras status in extrahepatic metastatic patients; (B) overall survival according to K-ras status in extrahepatic metastatic patients.

Abbreviations: WT, wild type; MT, mutated; mPFS, median progression-free survival; mOS, median overall survival; $\mathrm{HR}$, hazard ratio; Cl, confidence interval.

K-ras-mutation analysis was retrospective, which is common in randomized studies examining the role of biomarkers. Secondly, the number of patients in the overall population was small, resulting in imbalance parameters between WT and MT K-ras tumors. In addition, K-ras-status evaluation was performed only on primitive tumors.

In conclusion, this retrospective analysis found that chemotherapy plus bevacizumab is a reliable first-line therapeutic approach in $\mathrm{mCRC}$, regardless of whether metastases are liver only or also extrahepatic. Finally, K-ras status did not appear to affect the outcome of patients receiving antiangiogenic therapy, according to some literature reports, but not others. The reasons for the discrepancy between studies are not yet apparent or sufficiently powered. The importance of K-ras mutation status remains to be explored, and future studies will be required to answer this question. 
Table 2 Summary of K-ras data from studies of bevacizumab + chemotherapy in mCRC patients

\begin{tabular}{|c|c|c|c|c|c|c|c|}
\hline \multirow[t]{2}{*}{ Regimen } & \multirow{2}{*}{$\frac{\text { Ince et }_{\text {al }}{ }^{33}}{\text { IFL + BV }}$} & \multirow{2}{*}{ 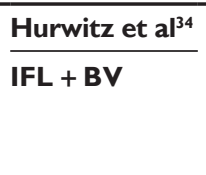 } & \multirow{2}{*}{$\begin{array}{l}\text { Díaz-Rubio et al }{ }^{35} \\
\mathrm{XELOX}+\mathrm{BV} \rightarrow \\
\mathrm{XELOX}+\mathrm{BV} / \mathrm{BV} \\
\text { alone }\end{array}$} & \multirow{2}{*}{$\frac{\text { Masi et al }^{36}}{\text { FOLFOXIRI + BV }}$} & \multirow{2}{*}{$\frac{\text { Tol et } \mathrm{al}^{37}}{\text { CapeOx + BV }}$} & \multirow{2}{*}{ 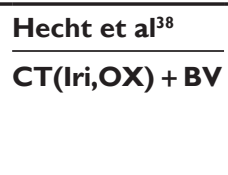 } & \multirow{2}{*}{$\begin{array}{l}{\text { Price et } \mathrm{al}^{39}}^{39} \text { Cape + BV } \\
\pm \text { MitC }\end{array}$} \\
\hline & & & & & & & \\
\hline WT K-ras* & $152 / 267$ & $85 / 402$ & $219 / 480$ & $34 / 57$ & $156 / 368$ & $104 / 525$ & $224 / 314$ \\
\hline MT K-ras* & $78 / 267$ & $44 / 402$ & I75/480 & $21 / 57$ & $108 / 368$ & $82 / 525$ & $90 / 314$ \\
\hline \multicolumn{8}{|l|}{ PFS, months } \\
\hline WT K-ras & NA & 13.5 & 10.9 & 13.6 & 10.6 & 11.5 & 8.8 \\
\hline MT K-ras & NA & 9.3 & 9.4 & 12.6 & 12.5 & II & 8.2 \\
\hline$P$-value & NA & NA & 0.0038 & NA & 0.80 & NA & NA \\
\hline \multicolumn{8}{|l|}{ OS, months } \\
\hline WT K-ras & 27.7 & 27.7 & 26.7 & 30.9 & 22.4 & 24.5 & 19.8 \\
\hline MT K-ras & 19.9 & 19.9 & 18.0 & NA & 24.9 & 19.3 & 17.6 \\
\hline$P$-value & NA & NA & 0.0002 & NA & 0.82 & NA & NA \\
\hline
\end{tabular}

Note: *Number of patients WT or MT K-ras/number of patients in study.

Abbreviations: mCRC, metastatic colorectal cancer; WT wild type; MT mutant; IFL irinotecan, 5-fluorouracil, and leucovorin; BV, bevacizumab; XELOX, capecitabine and oxaliplatin; FOLFOXIRI, 5-fluorouracil, oxaliplatin, and irinotecan; CapeOx, capecitabine and oxaliplatin; Iri, irinotecan; Ox, oxaliplatin; Cape, capecitabine; MitC, mitomycin C; WT wild-type; MT, mutated; NA, not available; PFS, progression-free survival; OS, overall survival; CT, chemotherapy.

\section{Disclosure}

The authors report no conflicts of interest in this work.

\section{References}

1. Lièvre A, Bachet JB, Le Corre D, et al. KRAS mutation status is predictive of response to cetuximab therapy in colorectal cancer. Cancer Res. 2006;66:3992-3995.

2. Amado RG, Wolf M, Peeters M et al. Wild-type KRAS is required for panitumumab efficacy in patients with metastatic colorectal cancer. J Clin Oncol. 2008;26:1626-1634.

3. McShane LM, Hayes DF. Publication of tumor marker research results: the necessity for complete and transparent reporting. J Clin Oncol. 2012;30:4223-4232.

4. Karapetis CS, Khambata-Ford S, Jonker DJ, et al. KRAS mutations and benefit from cetuximab in advanced colorectal cancer. $N$ Engl J Med. 2008;359:1757-1765.

5. Andreyev HJ, Norman AR, Cunningham D, et al. Kirsten ras mutations in patients with colorectal cancer: the 'RASCAL II' study. Br J Cancer. 2001;85:692-696.

6. Roth AD, Tejpar S, Delorenzi M, et al. Prognostic role of KRAS and BRAF in stage II and III resected colon cancer: results of the translational study on the PETACC-3, EORTC 40993, SAKK 60-00 Trial. J Clin Oncol. 2010;28:466-474.

7. Saridaki Z, Papadatos-Pastos D, Tzardi M, et al. BRAF mutations, microsatellite instability status and cyclin D1 expression predict metastatic colorectal patients' outcome. Br J Cancer. 2010;102: 1762-1768.

8. Souglakos J, Philips J, Wang R, et al. Prognostic and predictive value of common mutations for treatment response and survival in patients with metastatic colorectal cancer. Br J Cancer. 2009;101:465-472.

9. Tol J, Nagtegaal ID, Punt CJ. BRAF mutation in metastatic colorectal cancer. N Engl J Med. 2009;361:98-99.

10. Samowitz WS, Sweeney C, Herrick J, et al. Poor survival associated with the BRAF V600E mutation in microsatellite-stable colon cancers. Cancer Res. 2005;65:6063-6069.

11. Downward J. Targeting RAS signalling pathways in cancer therapy. Nat Rev Cancer. 2003;3:11-22.

12. Schubbert S, Shannon K, Bollag G. Hyperactive Ras in developmental disorders and cancer. Nat Rev Cancer. 2007;7:295-308.

13. Malumbres M, Barbacid M. RAS oncogenes: the first 30 years. Nat Rev Cancer. 2003;3:459-465.

14. Bos JL. Ras oncogenes in human cancer: a review. Cancer Res. 1989;49:4682-4689.
15. Rak J, Yu JL, Kerbel RS, Coomber BL. What do oncogenic mutations have to do with angiogenesis/vascular dependence of tumors? Cancer Res. 2002;62:1931-1934.

16. Mizukami Y, Kohgo Y, Chung DC. Hypoxia inducible factor-1 independent pathways in tumor angiogenesis. Clin Cancer Res. 2002;62:1931-1934.

17. Kabbinavar F, Hurwitz HI, Fehrenbacher L, et al. Phase II, randomized trial comparing bevacizumab plus fluorouracil (FU)/leucovorin (LV) with FU/LV alone in patients with MCRC. J Clin Oncol. 2003;21:60-65.

18. Kabbinavar FF, Schulz J, McCleod M, et al. Addition of bevacizumab to bolus fluorouracil and leucoverin in first-line metastatic colorectal cancer: results of a randomized phase II trial. J Clin Oncol. 2005;23:3697-3704.

19. Hurwitz H, Fehrenbacher L, Novontny W, et al. Bevacizumab plus irinotecan, fluorouracil and leucovorin for metastatic colorectal cancer. N Engl J Med. 2004;350:2335-2342.

20. Giantonio BJ, Catalano PJ, Neal J, et al. Bevacizumab in combination with oxaliplatin, fluorouracil and leucovorin (FOLFOX4) for previously treated metastatic colorectal cancer: results from the Eastern Cooperative Oncology Group Study E3200. J Clin Oncol. 2007;25:1539-1544.

21. Saltz LB, Clarke S, Díaz-Rubio E, et al. Bevacizumab in combination with oxaliplatin-based chemotherapy as first-line therapy in metastatic colorectal cancer: a randomized phase III study. J Clin Oncol. 2008;26:2013-2019.

22. Wong R, Cunningham D, Barbachano Y, et al. A multicentre study of capecitabine, oxaliplatin plus bevacizumab as perioperative treatment of patients with poor-risk colorectal liver-only metastases not selected for up-front resection. Ann Oncol. 2011;22:2042-2048.

23. Díaz-Rubio E, Gómez-España A, Massutí B, et al. First-line XELOX plus bevacizumab followed by XELOX plus bevacizumab or single agent bevacizumab as maintenance therapy in patients with metastatic colorectal cancer: the phase III MACRO TTD study. Oncologist. 2012;17:15-25.

24. Bennouna J, Sastre J, Arnold D, et al. Continuation of bevacizumab after progression in metastatic colorectal cancer (ML18147): a randomized phase III trial. Lancet Oncol. 2013;14:29-37.

25. Tie J, Lipton L, Desai J, et al. KRAS mutation is associated with lung metastasis in patients with curatively resected colorectal cancer. Clin Cancer Res. 2011;17:1122-1130.

26. Rossi L, Veltri E, Zullo A, et al. Bevacizumab plus chemotherapy in metastatic colorectal cancer patients treated in clinical practice. Future Oncol. 2012;8:1193-1197.

27. Sanger F, Nicklen F, Coulson AR. DNA sequencing with chainterminating inhibitors. Proc Natl Acad Sci US A. 1977;74:5463-5467. 
28. Tournigand C, André T, Achille E, et al. FOLFIRI followed by FOLFOX6 or the reverse sequence in advanced colorectal cancer: a randomized GERCOR study. J Clin Oncol. 2004;22:229-237.

29. Colucci G, Gebbia V, Paoletti G, et al. Phase III randomized trial of FOLFIRI versus FOLFOX4 in the treatment of advanced colorectal cancer: a multicenter study of the Gruppo Oncologico Dell'Italia Meridionale. J Clin Oncol. 2005;23:4866-4875.

30. Bendell JC, Bekaii-Saab TS, Cohn AL, et al. Treatment patterns and clinical outcomes in patients with metastatic colorectal cancer initially treated with FOLFOX-bevacizumab or FOLFIRI-bevacizumab: results from ARIES, a bevacizumab observational cohort study. Oncologist. 2012;17:1486-1495.

31. Modest DP, Stintzing S, Laubender RP, et al. Clinical characterization of patients with metastatic colorectal cancer depending on the KRAS status. Anticancer Drugs. 2011;22:913-918.

32. Nash GM, Gimbel M, Shia J, et al. KRAS mutation correlates with accelerated metastatic progression in patients with colorectal liver metastases. Ann Surg Oncol. 2010;17:572-578.

33. Ince WL, Jubb AM, Holden SN, et al. Association of KRAS, b-raf, and p53 status with the treatment effect of bevacizumab. J Natl Cancer Inst. 2005;97:981-989.

34. Hurwitz HI, Yi J, Ince W, Novotny WF, Rosen O. The clinical benefit of bevacizumab in metastatic colorectal cancer is independent of KRAS mutation status: analysis of phase III study of bevacizumab with chemotherapy in previously untreated metastatic colorectal cancer. Oncologist. 2009; 14:22-28.
35. Díaz-Rubio E, Gómez-España A, Massutí B, et al. Role of KRAS status in patients with metastatic colorectal cancer receiving first-line chemotherapy plus bevacizumab: a TTD group cooperative study. PLoS One. 2012;7:e47345.

36. Masi G, Loupakis F, Salvatore L, et al. Bevacizumab with FOLFOXIRI (irinotecan, oxaliplatin, fluorouracil, and folinate) as first-line treatment for metastatic colorectal cancer: a phase 2 trial. Lancet Oncol. 2011;11: $845-852$.

37. Tol J, Koopman M, Cats A, et al. Chemotherapy, bevacizumab and cetuximab in metastatic colorectal cancer. N Engl J Med. 2009;360: 563-570.

38. Hecht JR, Mitchell E, Chidiac T, et al. A randomized phase IIIB trial of chemotherapy, bevacizumab and panitumumab compared with chemotherapy and bevacizumab alone for metastatic colorectal cancer. $J$ Clin Oncol. 2009;27:672-680.

39. Price TJ, Hardingham JE, Lee CK, et al. Impact of KRAS and BRAF gene mutation status on outcomes from the phase III AGITG MAX trial of capecitabine alone or in combination with bevacizumab and mitomycin in advanced colorectal cancer. J Clin Oncol. 2011;29: 2675-2682.
OncoTargets and Therapy

\section{Publish your work in this journal}

OncoTargets and Therapy is an international, peer-reviewed, open access journal focusing on the pathological basis of all cancers, potential targets for therapy and treatment protocols employed to improve the management of cancer patients. The journal also focuses on the impact of management programs and new therapeutic agents and protocols on

\section{Dovepress}

patient perspectives such as quality of life, adherence and satisfaction. The manuscript management system is completely online and includes a very quick and fair peer-review system, which is all easy to use. Visit http://www.dovepress.com/testimonials.php to read real quotes from published authors. 